\title{
A case of presumed choroidal metastasis from carcinoid tumor treated by photodynamic therapy with verteporfin
}

This article was published in the following Dove Press journal:

Clinical Ophthalmology

8 October 2013

Number of times this article has been viewed

\author{
Setsuko Kawakami \\ Yoshihiro Wakabayashi \\ Hiroshi Goto \\ Department of Ophthalmology, Tokyo \\ Medical University, Tokyo, Japan
}

\begin{abstract}
We report a case of metastatic choroidal carcinoid tumor with favorable outcome after photodynamic therapy. A 75-year-old woman was presumptively diagnosed with bilateral choroidal metastases from carcinoid tumor. Although the tumor in the right eye showed a tendency toward rapid expansion and required aggressive treatment to preserve vision, the size was still small and we hesitated to use external-beam radiotherapy because of the risk of radiation retinopathy. Consequently, photodynamic therapy was performed on the right eye, resulting in drastic reduction of the size and height of the choroidal tumor. Good visual acuity was maintained after photodynamic therapy. Photodynamic therapy may be an effective treatment for choroidal metastasis from carcinoid tumor.
\end{abstract}

Keywords: choroid, choroidal metastases, photodynamic therapy, carcinoid tumor

\section{Introduction}

Uveal metastasis from carcinoid tumor constitutes a small proportion of all uveal metastases. ${ }^{1-3}$ Although photodynamic therapy (PDT) has been reported as a treatment for some cases of metastatic choroidal tumor, ${ }^{4}$ as far as we are aware, only one case report on PDT for choroidal metastasis of carcinoid tumor has been published. ${ }^{5}$ Here, we report a case of metastatic choroidal carcinoid tumor with favorable outcome after PDT.

\section{Case report}

A 75-year-old woman who noticed floaters in her left eye for 2 weeks was referred to Tokyo Medical University Hospital in September 2010. She had a history of abdominal surgery for colon cancer (well-differentiated adenocarcinoma) in 2007. At presentation, her best-corrected decimal visual acuity was 0.6 oculus dexter (OD) and 0.9 oculus sinister (OS). Fundus examination revealed an orange-yellow mass that was 8 disc diameter (DD) in size with no measurable height at the inferotemporal side of the fundus OD, and a yellow-white mass $12 \mathrm{DD}$ in size and $4.8 \mathrm{~mm}$ in height at the superior side of the fundus OS (Figure 1A and B). Fluorescein angiography of the left eye showed hyperfluorescence inside the mass from early to late phase (Figure 1C and D). Serum levels of carcinoembryonic antigen, cancer antigen 19-9, and cancer antigen 125 were within normal limits. A gallium-67 citrate scintigraphy scan showed no obvious abnormal uptake in the whole body including the eyes. Single-photon emission computed tomography with $\mathrm{N}$-isopropyl-p- $\left[{ }^{123} \mathrm{I}\right]$ iodoamphetamine, which is known to be useful for the diagnosis of uveal melanoma, ${ }^{6}$ demonstrated no abnormal uptake in the eyes.
Correspondence: Setsuko Kawakami Department of Ophthalmology, Tokyo Medical University, 6-7-I Nishi-shinjuku, Shinjuku-ku, Tokyo I60-0023, Japan

Tel +8I 333426 III ext 5880

Fax +8I 333469170

Email setsu@tokyo-med.ac.jp 

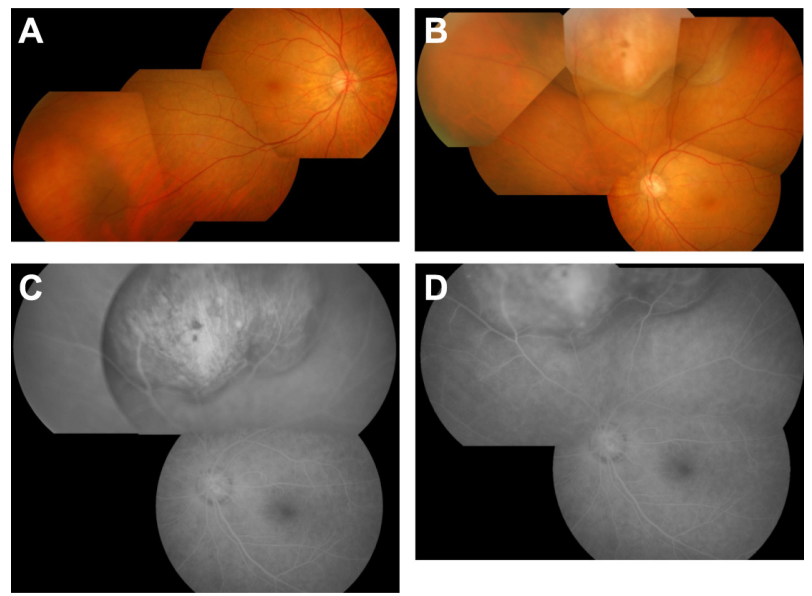

Figure I Findings at presentation. (A) Fundus photograph of right eye. An orangeyellow mass is shown at the inferotemporal side. (B) Fundus photograph of left eye. A yellow-white mass is shown at the superior side. (C) Early frame and (D) late frame of fluorescein angiogram of left eye. Note hyperfluorescence in the tumor region from the early phase to late phase.

In September 2011, the masses at the inferotemporal side OD and at the superior and inferior sides OS had enlarged, but visual acuity was preserved in both eyes. On both T1 and T2-weighted magnetic resonance images of the left orbit, iso-dense regions relative to the cerebral white matter were found consistent with the masses. A systemic workup to search for extraocular primary lesions revealed multiple nodules in the subcutaneous tissues of bilateral breasts on ultrasonography and neoplastic lesions in the right bronchial tubes on chest computed tomography. Histopathology of the tumor from a breast biopsy revealed foci of oval and spindle-shaped cells in alveolar and palisading arrangement (Figure 2), and that from a lung biopsy showed oval hypertrophic nuclei and proliferation of atypical epithelial cells in rosette-like arrangement. Immunohistochemical staining was positive for CD56,

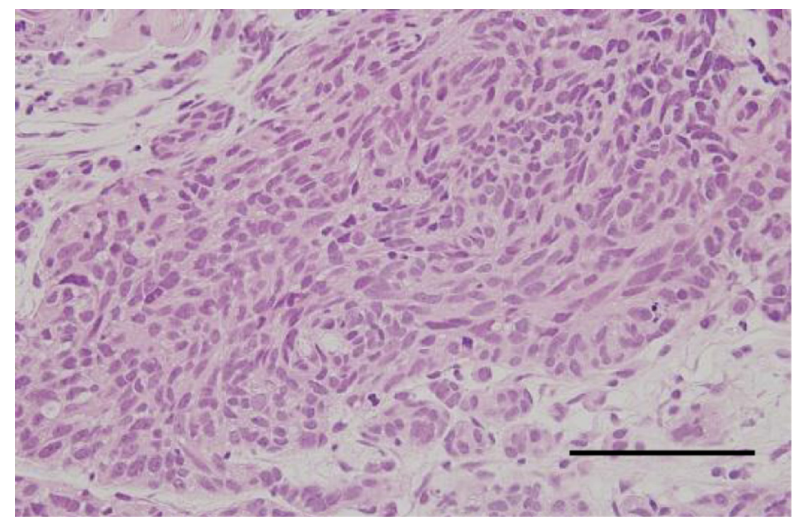

Figure 2 Histopathology of the tumor from a breast biopsy. Foci of oval and spindle-shaped cells are shown in alveolar and palisading arrangement. Notes: Hematoxylin and eosin staining; scale bar $=100 \mu \mathrm{m}$. chromogranin A, and synaptophysin. These imaging and histological findings were consistent with breast and lung carcinoid tumors.

From the clinical findings, general systemic workup, and clinical course, this case was presumptively diagnosed as choroidal metastasis from breast or lung carcinoid tumor. Fifteen months after the initial examination, the masses in both eyes expanded further. The mass at the inferotemporal side of the right eye was 20 DD in size and $3.5 \mathrm{~mm}$ in height. The mass at the superior side of left eye was $28 \mathrm{DD}$ in size and $14.9 \mathrm{~mm}$ in height, and the mass at the inferior side was $7 \mathrm{DD}$ in size and $5.5 \mathrm{~mm}$ in height. The left optic disc was invisible because of the enlarged mass, and best-corrected visual acuity was reduced to hand motion (Figure $3 \mathrm{~A}$ and $\mathrm{B}$ ). An indocyanine green angiogram of the right eye showed choroidal vessel staining inside the mass from the early phase, and a mixture of hyper- and hypofluorescence in the late phase (Figure 3C and D).

External-beam radiotherapy of $40 \mathrm{~Gy}$ was used to treat the tumor in the left eye. Although the tumor in the right eye showed a tendency toward rapid expansion and required aggressive treatment to preserve vision, the tumor was still small and we had reservations about using external-beam radiotherapy due to the risk of adverse effects such as radiation retinopathy. Consequently, PDT was performed on her right eye after obtaining informed consent.

Standard PDT was conducted with intravenous infusion of verteporfin at a dose of $6 \mathrm{mg} / \mathrm{m}^{2}$ body surface area over 10 minutes. Treatment parameters were $689 \mathrm{~nm}$ at $50 \mathrm{~J}$
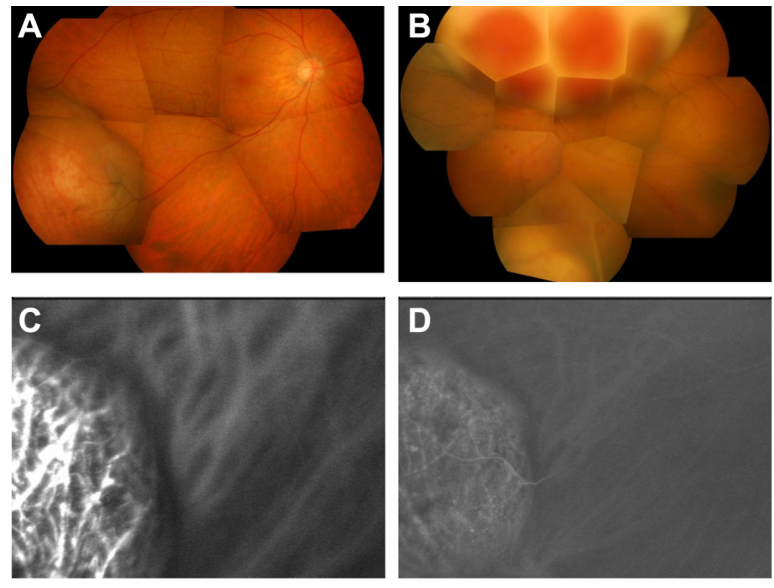

Figure 3 Findings at 15 months after presentation. (A) Fundus photographs of right eye and (B) left eye. The choroidal tumors are shown. The tumors have apparently enlarged in size compared with size at presentation. (C) Early frame and (D) late frame of indocyanine green angiogram of right eye. Choroidal vessels inside the tumor are stained from the early phase, with a mixture of hyperfluorescence and hypofluorescence in the late phase. 
$(600 \mathrm{~mW}) / \mathrm{cm}^{2}$ for an exposure time of 83 seconds. The diameter of each spot was $6,500 \mu \mathrm{m}$, and three spots with overlapping margin were administered. The tumor at the inferotemporal side was reduced to $7 \mathrm{DD}$ and no measurable height after treatment. Later, a new mass 4 DD in size appeared at the inferonasal side and remained unchanged. The tumor at the superior side of the left eye was reduced after radiotherapy and the optic disc became visible (Figure 4A and B). Best-corrected decimal visual acuity was $0.8 \mathrm{OD}$ and $50 \mathrm{~cm}$ hand movement $\mathrm{OS}$ at 14 months after PDT (30 months after the initial visit) and the patient's general condition was stable.

\section{Discussion}

Carcinoid tumor is a relatively rare low-grade neoplasm. Carcinoid tumors of the lung account for $1 \%-2 \%$ of all lung neoplasms. ${ }^{7}$ About $70 \%$ of all carcinoids are located in the major bronchi and the remainder in the periphery of the lungs. ${ }^{7}$ Breast carcinoids are also rare, accounting for less than $1 \%$ of breast cancers, and may be primary or metastatic. ${ }^{8}$ In the present case, both lung and breast carcinoid tumors were present; it remains unknown whether both were primary tumors. Carcinoid tumors commonly metastasize to lymph nodes, liver, and bone but rarely to the eye or orbit. ${ }^{9,10}$ Uveal metastasis is the most common intraocular malignancy and the majority originate from breast cancer in women and lung cancer in men. Uveal metastasis from carcinoid tumors constitutes only $2.2 \%$ of all uveal metastases. ${ }^{1-3}$ The survival outcome of metastatic uveal tumor is generally poor. The mean survival is 8 months from the establishment of ocular diagnosis in cases of primary lung cancer and 18 months in cases of primary breast cancer. ${ }^{11}$ However, a relatively long survival of 34 months has been reported in cases of primary carcinoid tumor. ${ }^{3}$ Uveal carcinoid metastasis may be the initial manifestation of carcinoid tumor in some patients, or the

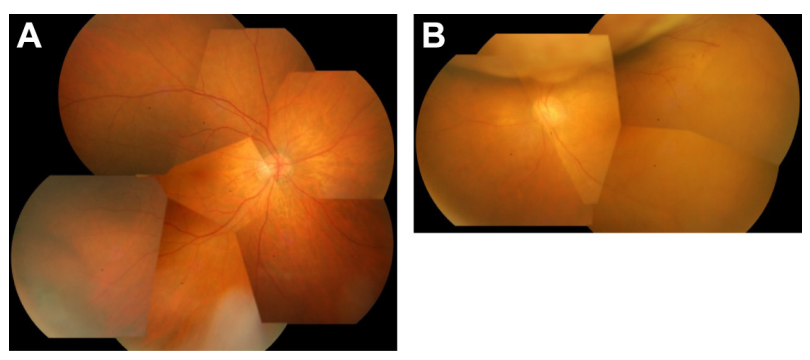

Figure 4 Findings after photodynamic therapy of right eye and external radiation therapy of left eye. (A) Fundus photograph of right eye 5 months after photodynamic therapy. The choroidal tumor at the inferior-temporal side has decreased in size compared with size before therapy. (B) Fundus photograph of left eye 5 months after external radiation therapy. The choroidal tumor has decreased in size and the optic disc is visible. late manifestation of advanced metastatic disease in others. ${ }^{5}$ Our case is compatible with the clinical course of choroidal metastasis from carcinoid tumor, because the tumor growth was quite slow and the general condition was maintained favorably compared with other metastatic tumors.

External-beam radiotherapy, photocoagulation, protonbeam irradiation, and brachytherapy have been used to treat choroidal metastasis from carcinoid tumors., ${ }^{3,12-14}$ PDT that targets vascular endothelial cells and causes intraluminal thrombosis ${ }^{15}$ was initially developed for the treatment of age-related macular degeneration. ${ }^{16}$ More recently, PDT has also been used for the treatment of choroidal metastases from cancers including breast cancer, lung cancer, and leiomyosarcoma. ${ }^{4,5,17-19}$ As far as we are aware, only one case of PDT for choroidal metastasis from carcinoid tumor has been reported previously. ${ }^{5}$ Choroidal metastasis has a hypervascular pattern, as demonstrated by color-flow mapping. ${ }^{20}$ Therefore, PDT may be effective for choroidal hemangioma and hypervascular choroidal tumors. ${ }^{21,22}$ Hemangiomas have vessels with a normal endothelial lining, in contrast to choroidal neovascularization of age-related macular degeneration. PDT also targets nonproliferative choroidal vessels. The greater blood volume in the dilated vessels of hemangioma may account for the efficacy of PDT for hemangioma. ${ }^{21,23}$

In a case series, PDT provided excellent control of choroidal metastasis with stabilization or improvement of visual acuity, with the exception of a few cases of intraretinal hemorrhage. ${ }^{4}$ In the case of PDT for choroidal metastasis from carcinoid tumor reported by Harbour, ${ }^{5}$ the tumor was reduced by $33 \%$ in size and $25 \%$ in height. In our case, the tumor was reduced by $65 \%$ in size while the height was reduced from $3.5 \mathrm{~mm}$ to a height not able to be measured, showing greater efficacy than in Harbour's case. Compared with PDT, radiotherapy has greater risk of causing various sight-threatening adverse effects and is not recommended for patients with good visual acuity. The present case and a previously reported case ${ }^{5}$ thus indicate that PDT is an effective treatment for choroidal metastases of carcinoid tumors. However, because the energy of PDT has a limited depth of penetration, its efficacy is limited when the metastatic tumors are thick or extensive. It would be difficult to treat these cases with PDT alone. Further studies may establish the indications for PDT in the treatment of choroidal metastases from carcinoid and other tumors.

In general, patients with choroidal metastasis from carcinoid tumor survive for a fairly long time after onset of ocular symptoms. The present case suggests that PDT may be 
effective in controlling the intraocular lesion and maintaining good vision and quality of life.

\section{Disclosure}

The authors report no conflicts of interest in this work.

\section{References}

1. Shields JA, Shields CA. Metastatic tumors to the intraocular structures. In: Intraocular Tumors: Atlas and Textbook. 2nd ed. Philadelphia, PA: Lippincott Williams \& Wilkins; 2008:198-227.

2. Shields CL, Shields JA, Gross NE, Schwartz GP, Lally SE. Survey of 520 eyes with uveal metastasis. Ophthalmology. 1997;104(8): $1265-1276$.

3. Harbour JW, De Potter P, Shields CL Shields JA. Uveal metastasis from carcinoid tumor. Clinical observations in nine cases. Ophthalmology. 1994;101(6):1084-1090.

4. Kaliki S, Shields CL, Al-Dahmash SA, Mashayekhi A, Shields JA. Photodynamic therapy for choroidal metastasis in 8 cases. Ophthalmology. 2012;119:1218-1222.

5. Harbour JW. Photodynamic therapy for choroidal metastasis from carcinoid tumor. Am J Ophthalmol. 2004;137(6):1143-1145.

6. Goto H. Clinical efficacy of 123I-IMP SPECT for the diagnosis of malignant uveal melanoma. Int J Clin Oncol. 2004;9(2):74-78.

7. Hage R, de la Rivière AB, Seldenrijk CA, van den Bosch JM. Update in pulmonary carcinoid tumors: a review article. Ann Surg Oncol. 2003;10(6):697-704.

8. Upalakalin JN, Collins LC, Tawa N, Parangi S. Carcinoid tumors in the breast. Am J Surg. 2006;191(6):799-805.

9. Godwin JD 2nd. Carcinoid tumors. An analysis of 2,837 cases. Cancer. 1975;36(2):560-569.

10. Martin RG. Management of carcinoid tumors. Cancer. 1970;26(3): 547-551.

11. Shields JA, Shields CL. Metastatic tumors to the intraocular structures. In: Intraocular Tumors: A Text and Atlas. Philadelphia, PA: WB Saunders, 1992:207-238

12. Riddle PJ, Font RL, Zimmerman LE. Carcinoid tumors of the eye and orbit: a clinicopathologic study of 15 cases, with histochemical and electron microscopic observations. Hum Pathol. 1982;13(5): $459-469$.
13. Gragoudas ES, Carroll JM. Multiple choroidal metastasis from bronchial carcinoid treated with photocoagulation and proton beam irradiation. Am J Ophthalmol. 1979;87(3):299-304.

14. Minning CA Jr, Davidorf FH, Makley TA Jr, Bruce RA Jr. Metastatic carcinoid to the choroid. Retina. 1982;2(4):223-230.

15. Schmidt-Erfurth U, Hasan T, Gragoudas E, Michaud N, Flotte TJ, Birngruber R. Vascular targeting in photodynamic occlusion of subretinal vessels. Ophthalmology. 1994;101(12):1953-1961.

16. [No authors listed] Photodynamic therapy of subfoveal choroidal neovascularization in age-related macular degeneration with verteporfin: one-year results of 2 randomized clinical trials -TAP report. Treatment of age-related macular degeneration with photodynamic therapy (TAP) Study Group. Arch Ophthalmol. 1999;117(10):1329-1345.

17. Soucek P, Cihelkova I. Photodynamic therapy with Verteporfin in subfoveal choroidal metastasis of breast carcinoma (a controlled case). Neuro Endocrinol Lett. 2006;27(6):725-728.

18. Isola V, Pece A, Pierro L. Photodynamic therapy with verteporfin of choroidal malignancy from breast cancer. Am J Ophthalmol. 2006;142(5):885-887.

19. Mauget-Faÿsse M, Gambrelle J, Quaranta-El Maftouhi M, Moullet I. Photodynamic therapy for choroidal metastasis from lung adenocarcinoma. Acta Ophthalmol Scand. 2006;84(4):552-554.

20. Neudorfer M, Waisbourd M, Anteby I, et al. Color flow mapping: a non-invasive tool for characterizing and differentiating between uveal melanomas and choroidal metastases. Oncol Rep. 2011;25(1): 91-96.

21. Schmidt-Erfurth UM, Michels S, Kusserow C, Jurklies B, Augustin AJ. Photodynamic therapy for symptomatic choroidal hemangioma: visual and anatomic results. Ophthalmology. 2002;109:22842294.

22. Boixadela A, García-Arumí J, Martínes-Castillo V, et al. Prospective clinical trial evaluating the efficacy of photodynamic therapy for symptomatic circumscribed choroidal hemangioma. Ophthalmology. 2009;116(1):100-105.

23. Zhang Y, Liu W, Fang Y, et al. Photodynamic therapy for symptomatic choroidal hemangioma: visual and anatomic results. Am J Ophthalmol. 2010;150(5):710-715. e1.
Clinical Ophthalmology

\section{Publish your work in this journal}

Clinical Ophthalmology is an international, peer-reviewed journal covering all subspecialties within ophthalmology. Key topics include: Optometry; Visual science; Pharmacology and drug therapy in eye diseases; Basic Sciences; Primary and Secondary eye care; Patient Safety and Quality of Care Improvements. This journal is indexed on Submit your manuscript here: http://www.dovepress.com/clinical-ophthalmology-journal

\section{Dovepress}

PubMed Central and CAS, and is the official journal of The Society of Clinical Ophthalmology (SCO). The manuscript management system is completely online and includes a very quick and fair peer-review system, which is all easy to use. Visit http://www.dovepress.com/ testimonials.php to read real quotes from published authors. 